\title{
Structural impact of armor monoblock dimensions on the failure behavior of ITER- type divertor target components: Size matters.
}

\author{
Muyuan Li, Jeong-Ha You* \\ Max-Planck-Institut für Plasmaphysik, Boltzmannstr.2, 85748 Garching, Germany
}

\begin{abstract}
Plenty of high-heat-flux tests conducted on tungsten monoblock type divertor target mock-ups showed that the threshold heat flux density for cracking and fracture of tungsten armor seems to be related to the dimension of the monoblocks. Thus, quantitative assessment of such size effects is of practical importance for divertor target design. In this paper, a computational study about the thermal and structural impact of monoblock size on the plastic fatigue and fracture behavior of an ITER-type tungsten divertor target is reported. As dimensional parameters, the width and thickness of monoblock, the thickness of sacrificial armor, and the inner diameter of cooling tube were varied. Plastic fatigue lifetime was estimated for the loading surface of tungsten armor and the copper interlayer by use of a cyclic-plastic constitutive model. The driving force of brittle crack growth through the tungsten armor was assessed in terms of J-integral at the crack tip. Decrease of the monoblock width effectively reduced accumulation of plastic strain at the armor surface and the driving force of brittle cracking. Decrease of sacrificial armor thickness led to decrease of plastic deformation at the loading surface due to lower surface temperature, but the thermal and mechanical response of the copper interlayer was not affected by the variation of armor thickness. Monoblock with a smaller tube diameter but with the same armor thickness and shoulder thickness experienced lower fatigue load. The predicted trends were in line with the experimental observations.
\end{abstract}

Keywords: divertor target, tungsten armor, high heat flux loads, fracture mechanics, deep cracking, low cycle fatigue

*Corresponding author: you@ipp.mpg.de (Jeong-Ha You) 


\section{Introduction}

Water-cooled full-tungsten monoblock equipped with a copper alloy cooling tube is the reference design concept adopted for the plasma-facing components (PFCs) of the vertical target for ITER divertor [1]. The ITER-type full-tungsten divertor PFC consists of ca. 2 meter-long longitudinal arrays of rectangular tungsten monoblocks as armor equipped with a penetrating cooling tube of $\mathrm{CuCrZr}$ alloy as heat sink which is joined to the monoblocks via a stress-relieving soft copper interlayer (see Figure 1). Currently, the ITER-type target PFC design is also considered as the baseline design concept for the European DEMO divertor while several novel design concepts are being developed as well in parallel [2].

The alteration of armor material option for the ITER divertor from previously considered carbon composites to tungsten posed an engineering challenge with respect to the high-heat-flux (HHF) performance under transient thermal loads. For the ITER divertor the peak surface heat flux is expected to reach $20 \mathrm{MW} / \mathrm{m}^{2}$ during a slow transient event ( 10 s) and roughly $1 \mathrm{GW} / \mathrm{m}^{2}$ during an edge localized mode ( $<1 \mathrm{~ms})$. The design specifications imposed on the ITER divertor targets are 5000 stationary loading cycles at $10 \mathrm{MW} / \mathrm{m}^{2}$ and 300 heat pulses at $20 \mathrm{MW} / \mathrm{m}^{2}$. It is noted that the same requirements with regard to HHF performance were assumed tentatively for the design of European DEMO divertor target PFCs [3].

Previous HHF test campaigns conducted on the ITER-type tungsten divertor PFC mock-ups demonstrated that the specifications were fulfilled for both the normal and transient loading conditions $[4,5,6,7,8,9,10,11]$. However, it was also observed that at $20 \mathrm{MW} / \mathrm{m}^{2}$ the tungsten armor often underwent macroscopic fracture exhibiting deep cracking from the surface down to the cooling tube within 1000 load cycles. Furthermore, formation of microscopic voids and interfacial cracks was found in the copper interlayer after the cyclic HHF tests at $20 \mathrm{MW} / \mathrm{m}^{2}$.

Recent computational studies [12,13,14] based on the finite element simulation of structural failure clarified the possible mechanism of the armor deep cracking and the microscopic damage of the interlayer observed after HHF tests of ITER divertor PFC mock-ups at $20 \mathrm{MW} / \mathrm{m}^{2}$. According to these studies, the deep cracking of armor is the result of dramatically recrystallization of the armor surface causing softening and plastic fatigue of the surface layer, which can lead to crack initiation and growth assisted by the plastically induced local tensile residual stress at the crack tip. It was also shown that the large plastic strain variation (alternating 
plasticity) of the copper interlayer is the most likely cause of the fatigue damage observed in the copper interlayer.

Although the ITER divertor PFCs were shown to fulfill the prescribed specifications with regard to HHF performance, it may be still desirable for the designers working on DEMO divertor PFCs to enhance the HHF performance as much as possible beyond the specification, since the current design efforts for DEMO reactors are subject to significant uncertainty with regard to operation scenarios and thus loads on divertor. Fabrication quality of materials and components is surely a critical factor, but the technical improvement has been a slow evolution process. An alternative approach would be to optimize the geometry, in particular, the dimension of PFCs.

The typical cross-sectional dimension of the mock-ups used in the previous HHF tests conducted for ITER full tungsten divertor target qualification program was $28 \times 28 \mathrm{~mm}^{2}$. Beside this typical dimension, a smaller tungsten diverter has been tested intensively at the beginning of this century. Tungsten monoblock divertors (monoblock dimension $(w \times h \times t): 22 \times 24 \times 4 \mathrm{~mm}, d=10 \mathrm{~mm})$ manufactured by CEA and ENEA with $\mathrm{W}-1 \% \mathrm{La}_{2} \mathrm{O}_{3}$ as well as the monoblocks manufactured by Plansee with thin tungsten lamellae of $0.2 \mathrm{~mm}$ survived 1000 cycles at $18 \mathrm{MW} / \mathrm{m}^{2}$ at unirradiated and irradiated states [15]. The HHF conditions were performed with electron beam facility JUDITH and tested tungsten monoblocks did not show any degradation of the fatigue performance [15]. It seems that a smaller monoblock has a better material performance. However, due to the difference in testing conditions, material grades and designs, it is difficult to draw a clear conclusion on the impact of tungsten monoblock dimension. Therefore it is of great interest to perform numerical simulations for a better understanding of the impact of tungsten monoblock dimension and deliver quantitative predictions for the divertor design. In the literature, a design study of the ITER-like monoblock for optimizing dimensions was found [16] concerning the thermo-mechanical behavior of the materials. But their work was focused on the material behavior of the cooling tube. A rigorous numerical study on the impact of monoblock dimension concerning the thermo-mechanical and fracture behaviors of tungsten armor and copper interlayer seems to be missing.

In this paper, a design-study is presented where the effect of monoblock size and armor thickness on the failure behavior of a reference ITER-type divertor target PFC is discussed. Comparative evaluations are delivered for different dimensions in terms of two major failure modes, namely, crack driving force in the armor and the fatigue lifetime of the interlayer. 


\section{Model for the finite element simulation}

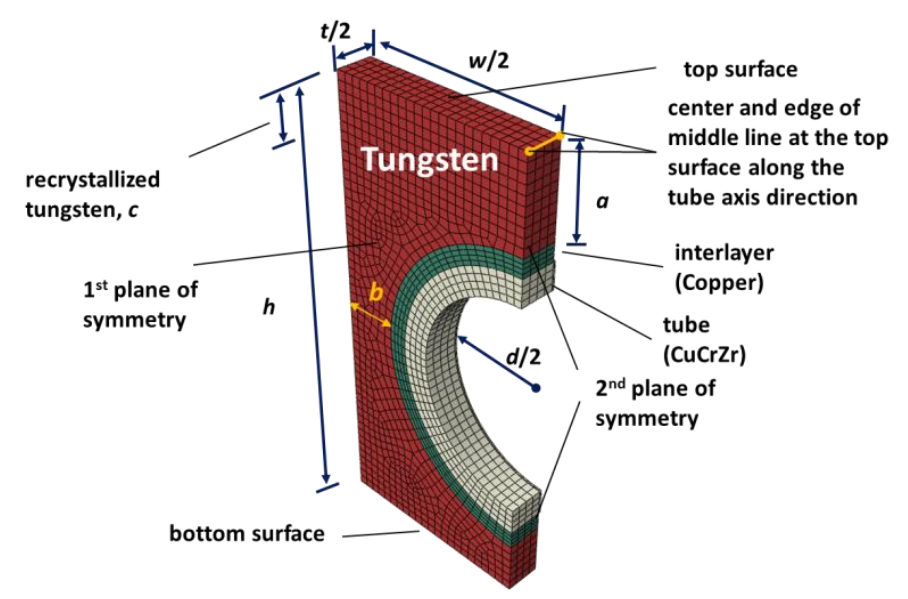

Figure 1. Finite element model with mesh showing the symmetry quarter model of the reference divertor target PFC design considered in this study. $w$ : monoblock width, $t$ : monoblock thickness, $h$ : monoblock height, $a$ : armor thickness, $b$ : side thickness of the armor, $c$ : thickness of the recrystallized layer and $d$ : cooling tube diameter.

Parametric thermal and structural HHF simulations were carried out by means of finite element analysis (FEA). In Figure 1 the finite element model with mesh is illustrated showing the symmetry quarter part of the reference PFC model used. This model is the ITER-type monoblock design being considered for European DEMO divertor target as baseline option [16]. The model consists of the same constituent materials as in the ITER divertor target. For comparative estimations the dimensional parameters were selected as follows:

The width of monoblock(w): $23 \mathrm{~mm}$ and $28 \mathrm{~mm}$,

The thicknesses of the monoblock $(t): 4 \mathrm{~mm}$ and $12 \mathrm{~mm}$,

The sacrificial armor thickness $(a)$ : from 1 to $10 \mathrm{~mm}$,

The side thickness of the armor $(b): 3 \mathrm{~mm}$.

The inner diameter of the cooling tube $(d): 10 \mathrm{~mm}$ and $12 \mathrm{~mm}$,

The thicknesses of copper interlayer and copper alloy tube are fixed to 1 and $1.5 \mathrm{~mm}$, respectively. These dimensional ranges basically cover the design space of the current ITER and DEMO divertor target PFCs. 
For the FEA simulations commercial code ABAQUAS [17] was employed. Quadratic solid brick element (20 nodes) was used. A combined nonlinear isotropic and (Frederick-Armstrong type) kinematic hardening model and a kinematic hardening model were applied for copper and the copper alloy, respectively, while ideal plasticity was assumed for tungsten. Temperaturedependent materials data were used. Selected materials parameters are listed in Table 1 [18, 19, 20].

Table 1. Materials data and parameters at selected temperatures $[\mathbf{1 8 , ~ 1 9 , 2 0 ] .}$

\begin{tabular}{|c|c|c|c|c|c|c|c|c|}
\hline & \multicolumn{4}{|c|}{ Tungsten $^{1}$ (recrystallized ${ }^{2}$ ) } & \multicolumn{2}{|c|}{$\mathrm{CuCrZr^{3 }}$} & \multicolumn{2}{|c|}{ Copper } \\
\hline & $20^{\circ} \mathrm{C}$ & $400^{\circ} \mathrm{C}$ & $1200^{\circ} \mathrm{C}$ & $2000^{\circ} \mathrm{C}$ & $20^{\circ} \mathrm{C}$ & $500^{\circ} \mathrm{C}$ & $20^{\circ} \mathrm{C}$ & $400^{\circ} \mathrm{C}$ \\
\hline Young's modulus (GPa) & 398 & 393 & 256 & 285 & 127.5 & 106 & 115 & 95 \\
\hline Yield stress (MPa) & $\begin{array}{l}1384 \\
(377)\end{array}$ & $\begin{array}{c}947 \\
(362)\end{array}$ & $\begin{array}{c}346 \\
(223)\end{array}$ & $\begin{array}{c}57 \\
(70)\end{array}$ & 407 & 233 & 56 & 31 \\
\hline $\begin{array}{l}\text { Heat conductivity } \\
(\mathrm{W} / \mathrm{mK})\end{array}$ & 173 & 140 & 105 & 99 & 318 & 346 & 401 & 374 \\
\hline $\begin{array}{l}\text { Coefficient of thermal } \\
\text { expansion }\left(10^{-6} / \mathrm{K}\right)\end{array}$ & 4.5 & 4.63 & 4.98 & 5.43 & 16.7 & 18.4 & 16.7 & 18.2 \\
\hline $\begin{array}{r}\text { Material parameters e } \\
\text { Armstrong constitutive } \\
\text { cop }\end{array}$ & $\begin{array}{l}\text { tering } t \\
\text { model } \mathrm{f} \\
\mathrm{er}^{4} \text {. }\end{array}$ & $\begin{array}{l}\text { Frede } \\
\text { CuCr2 }\end{array}$ & $\begin{array}{l}\text { ck- } \\
\text { and }\end{array}$ & $\begin{array}{c}\sigma_{0} \\
(\mathrm{MPa}) \\
\mathrm{Q} \\
(\mathrm{MPa}) \\
\mathrm{b} \\
\mathrm{C}(\mathrm{MPa}) \\
\gamma\end{array}$ & $\begin{array}{c}356 \\
- \\
- \\
41764 \\
521\end{array}$ & $\begin{array}{c}238 \\
- \\
- \\
7549 \\
352\end{array}$ & $\begin{array}{c}3 \\
76 \\
\\
8 \\
64257 \\
888\end{array}$ & $\begin{array}{c}3 \\
\\
36 \\
\\
25 \\
31461 \\
952\end{array}$ \\
\hline
\end{tabular}

${ }^{1}$ Rolled and stress-relieved state.

${ }^{2}$ The ultimate tensile strength of recrystallized tungsten is used as yield stress assuming a prehardened state.

${ }^{3} \mathrm{CuCrZr}$-IG (here IG - ITER Grade) alloy solution annealed, cold worked and aged condition

${ }^{4}$ Softened by annealing at $700^{\circ} \mathrm{C}$ for $1 \mathrm{~h}$.

A typical full thermal history which a divertor target PFC would experience during fabrication and HHF loading was considered for the simulation. There are four distinct stages of temperature loading as illustrated schematically in Figure 2. 
Fabrication: uniform cooling from stress-free temperature to room temperature (only once), Stand-by: quasi-uniform preheating from room temperature to coolant temperature (e.g. after maintenance),

HHF loading: non-uniform heating at 10 or $20 \mathrm{MW} / \mathrm{m}^{2}$ (regular operation),

Pulse-off duration: uniform cooling at coolant temperature (regular operation).

The stress-free temperature was assumed to be $580{ }^{\circ} \mathrm{C}$, which is the typical joining temperature in the HRP (Hot Radial Pressing) process, one of the potential fabrication techniques for PFCs [8].

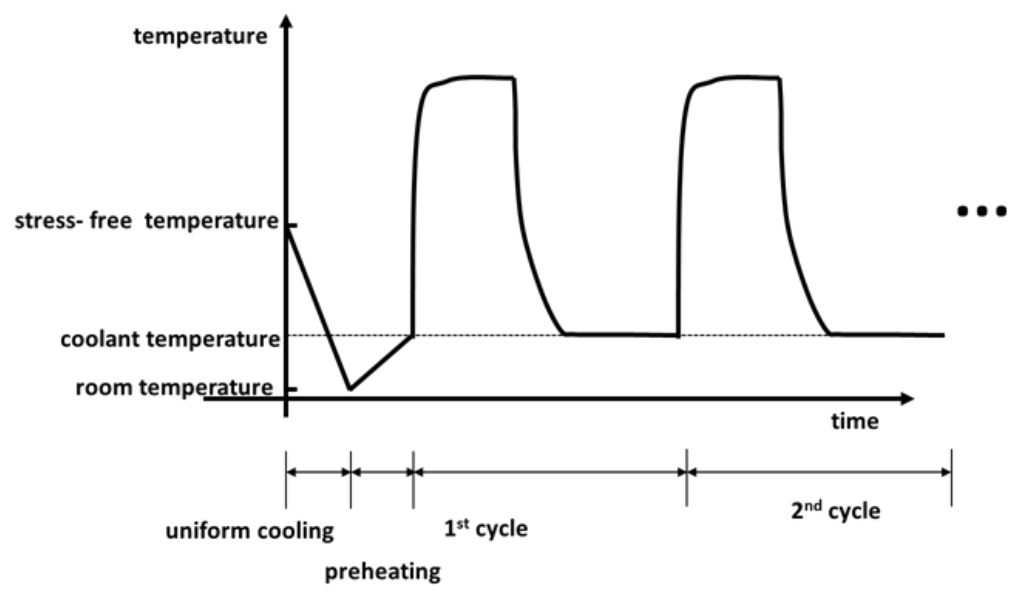

Figure 2. Schematic illustration of the thermal history considered for the simulation.

The hydraulic boundary conditions assumed for the water coolant are as follows:

Coolant temperature: $150^{\circ} \mathrm{C}$,

Water pressure: $5 \mathrm{MPa}$,

Water velocity: $16 \mathrm{~m} / \mathrm{s}$.

These coolant hydraulic conditions are currently considered for the European DEMO divertor PFC [2]. The heat transfer coefficient was calculated using Sieder/Tate [21] and CEA/Thom [22] correlations (with swirl tape).

The nodes on the both end sections of the tube were constrained to force a planar displacement in the longitudinal direction. For fracture mechanical computation a symmetry half model was used instead of the quarter model.

\section{Results and discussion}




\subsection{Thermal effect of monoblock dimension}

In Table 2 the maximum temperature values in the individual parts of the PFC assessed for four different monoblock dimensions (unit: $\mathrm{mm}, t=4 / w=23 ; t=12 / w=23 ; t=4 / w=28 ; t=12 / w=28$ ) and two levels of HHF loading (10 and $\left.20 \mathrm{MW} / \mathrm{m}^{2}\right)$ are summarized. For brevity, the armor thickness $a(5 \mathrm{~mm})$ and the tube inner diameter $d(12 \mathrm{~mm})$ were fixed.

It is seen that the width $w$ has significant influence over the armor temperature in the nearsurface region while the thickness seems to have only minor influence. Decreasing the width from 28 to $23 \mathrm{~mm}$ leads to decrease of the maximum armor temperature roughly by 100 and $200{ }^{\circ} \mathrm{C}$ at 10 and $20 \mathrm{MW} / \mathrm{m}^{2}$, respectively. This temperature decrease is primarily due to the shortening of heat conduction paths. The slight decrease of armor temperature in the thinner monoblock $(t=4 \mathrm{~mm})$ is attributed to the decrease in the ratio of the surface area being heated to the area of inner tube wall being cooled, since the number of gaps $(0.25 \mathrm{~mm})$ between monoblocks increases when the thickness is reduced. On the contrary, the dimension effect on temperature is strongly attenuated in the heat sink. The difference in the maximum temperatures among the four cases is not larger than $25^{\circ} \mathrm{C}$ at the most.

Another quantity of interest is the depth of recrystallized zone where the material's yield stress is considerably reduced by softening. Cold-worked tungsten is known to undergo recrystallization roughly at $1300{ }^{\circ} \mathrm{C}$. Taking this into account, recrystallized layer depth $c$ is estimated to range from $1 \mathrm{~mm}(w=23 \mathrm{~mm})$ to $1.5 \mathrm{~mm}(w=28 \mathrm{~mm})$ at the mid-position of the armor top surface. Of course, $c$ becomes larger when the armor thickness is increased. For simplicity, $c$ is set to be 1 for all cases at $20 \mathrm{MW} / \mathrm{m}^{2}$.

Table 2. Maximum temperature $\left({ }^{\circ} \mathrm{C}\right)$ in the individual parts of the PFC assessed for four different monoblock dimensions and two levels of HHF loading.

\begin{tabular}{|l|c|c|c|c|c|}
\hline \multirow{2}{*}{ W armor } & $\begin{array}{c}\text { Load } \\
\left(\mathrm{MW} / \mathrm{m}^{2}\right)\end{array}$ & \multicolumn{4}{|c|}{ Monoblock dimension $(\mathrm{mm})$} \\
\cline { 2 - 6 } & 10 & $t=4, w=23$ & $t=12, w=23$ & $t=4, w=28$ & $t=12, w=28$ \\
\cline { 2 - 6 } & 20 & 1723 & 863 & 962 & 970 \\
\hline \multirow{2}{*}{ Cu interlayer } & 10 & 336 & 342 & 350 & 356 \\
\cline { 2 - 6 } & 20 & 506 & 514 & 524 & 531 \\
\hline
\end{tabular}




\begin{tabular}{|l|l|l|l|l|l|}
\hline \multirow{2}{*}{ CuCrZr tube } & 10 & 301 & 306 & 313 & 319 \\
\cline { 2 - 6 } & 20 & 432 & 439 & 445 & 452 \\
\hline
\end{tabular}

3.2. Mechanical effect of monoblock dimension on tungsten armor failure

At $10 \mathrm{MW} / \mathrm{m}^{2}$, the maximum temperature of the armor is so low $\left(<970{ }^{\circ} \mathrm{C}\right)$ in all cases that the yield stress remains high enough to avoid plastic yield and the whole armor behaves elastically. At $20 \mathrm{MW} / \mathrm{m}^{2}$, however, the armor surface temperature by far exceeds the recrystallization limit leading to drastic decrease of yield stress and thus to considerable plastic flow in the top surface layer.

Figure 3 shows the incremental evolution of plastic deformation at the armor top surface during the first five $\mathrm{HHF}$ loading cycles at $20 \mathrm{MW} / \mathrm{m}^{2}$. Plotted are accumulated equivalent plastic strain values computed at two selected surface positions, namely, at the center (left) and the edge (right) of the axial mid-line as indicated in Figure 1. Plastic strain values obtained for four different monoblock dimensions are compared.
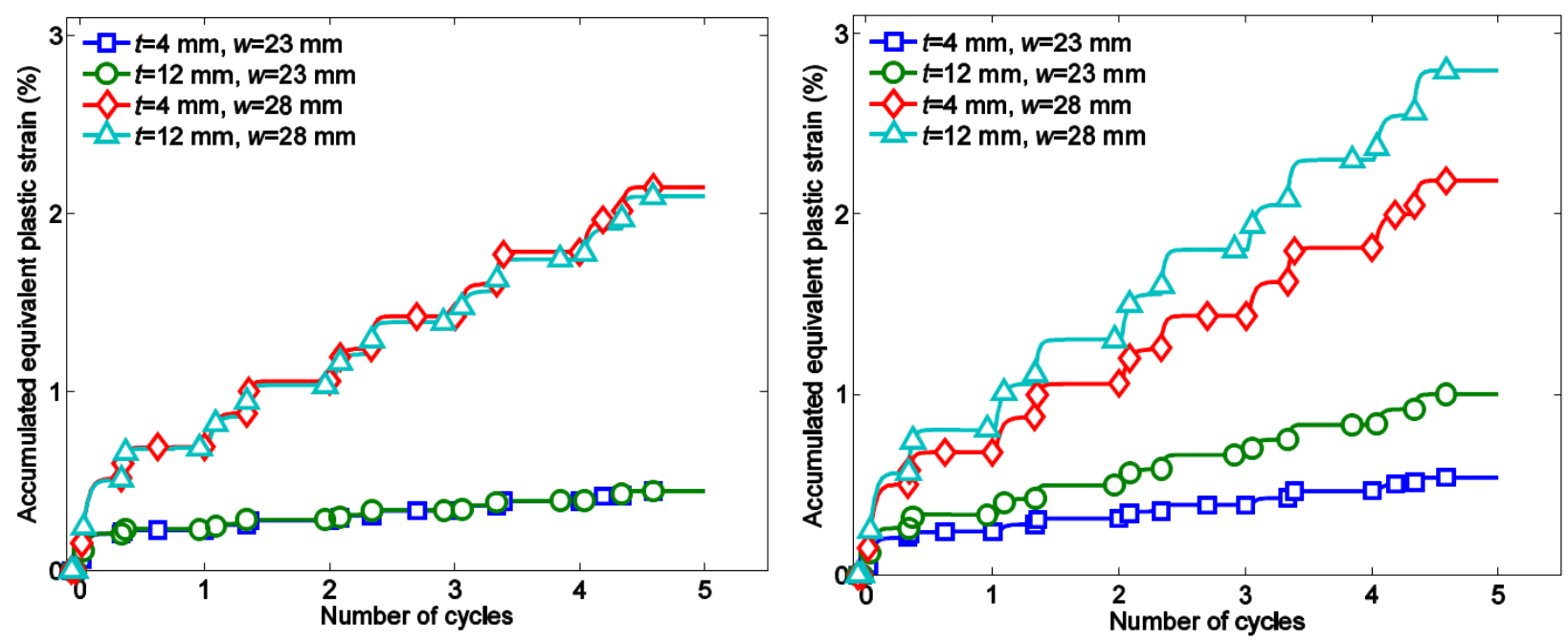

Figure 3. Incremental evolution of plastic deformation at the armor top surface during the first five HHF loading cycles (at $20 \mathrm{MW} / \mathrm{m}^{2}$ ).

Figure 3 shows significant dimension effect, in particular, with respect to monoblock width at both positions. It is clearly found that the armor surface with the larger width ( $w=28 \mathrm{~mm}$ ) experiences much larger cyclic plastic straining in terms of both total magnitude and increment (amplitude). Furthermore, at the edge position of the surface, also the monoblock thickness $t$ has 
considerable impact on both the magnitude and the increment of plastic strain, which increase as the thickness increases from 4 to $12 \mathrm{~mm}$. On the contrary, the thickness $t$ has negligible effect at the center position.

The incremental steps of accumulated equivalent plastic strain reflect the amplitude of individual plastic strain components at the corresponding load cycles and as such are the measure of plastic fatigue load. Plastic fatigue lifetime of the armor surface can be estimated taking the stabilized plastic strain increment. This lifetime may be interpreted as the number of HHF load cycles to the initiation of a surface crack with the critical size being large enough for the crack to extend further by fatigue crack growth during subsequent HHF loading. It has been shown that such a macroscopic armor cracking mechanism is theoretically possible at $20 \mathrm{MW} / \mathrm{m}^{2}$, where plastically induced local tensile stress field at the crack tip plays a key role in crack growth [12]. Therefore, it is highly desired to mitigate the plastic fatigue of armor surface to impede armor cracking.

Table 3 summarizes the calculated equivalent plastic strain range (\%) and corresponding fatigue lifetime at $20 \mathrm{MW} / \mathrm{m}^{2}$ estimated at the center and edge position on the mid-line of the armor top surface. The material data (fatigue curve of recrystallized tungsten) used for lifetime estimation was obtained at room temperature where tungsten is brittle. Thus, the estimates of life given here are obviously conservative (underestimated fatigue life) and should be regarded only indicative of the trend. It is also noted that each lifetime indicates the number of load cycles to be counted after armor surface has gotten fully recrystallized. To reach a fully recrystallized microstructure by a cumulative overheating effect through slow transient events, whose duration time amounts only a few seconds per pulse, the armor surface would need many load cycles additionally at 20 $\mathrm{MW} / \mathrm{m}^{2}$.

Table 3 Calculated equivalent plastic strain range [\%] (corresponding fatigue lifetime*) at 20 $\mathrm{MW} / \mathrm{m}^{2}$ estimated at the center and edge position on the mid-line of the armor top surface. Each lifetime indicates the number of load cycles to be counted after armor has been fully recrystallized for which many load cycles will be additionally needed at $20 \mathrm{MW} / \mathrm{m}^{2}$.

\begin{tabular}{|c|c|c|c|c|}
\hline Dimension $(\mathrm{mm})$ & $t=4, w=23$ & $t=12, w=23$ & $t=4, w=28$ & $t=12, w=28$ \\
\hline Edge & $0.039(511)$ & $0.084(37)$ & $0.188(2)$ & $0.247(1)$ \\
\hline Center & $0.028(1561)$ & $0.027(1611)$ & $0.181(2)$ & $0.176(3)$ \\
\hline
\end{tabular}


*The lifetime was assessed using the fatigue data of tungsten at room temperature [20] which yields conservative estimates.

It is found that the fatigue lifetime at the armor surface does exhibit a very strong dependence on the monoblock dimension. The combination of smaller cross section width $(w=23)$ and smaller axial thickness $(t=4 \mathrm{~mm})$ leads to significantly increased fatigue resistance. The difference in fatigue life between the monoblocks with the largest and the smallest size amounts a factor of 500. Taking the preceding load cycles needed for recrystallization into account, the risk of armor surface cracking due to slow transient HHF loads does not seem to be a critical issue for the small size monoblock inasmuch as such a specification is considered as adopted for the ITER divertor.

Assuming that a surface crack with a critical size has once been created by a certain cause, the impact of slow transient HHF loads on crack growth would be an important issue with respect to the structural integrity of the armor. In this context, the influence of monoblock size on the crack driving force is of interest.

Figure 4 shows the J-integral values at the tip of a crack initiated at the armor surface and extending in the vertical direction. The J-integral values are plotted for a range of crack length from 0.5 to $2.5 \mathrm{~mm}$ and for four different combinations of monoblock width and thickness. The left graph shows the J-integral values estimated at the symmetry plane while the right one at the free surface edge. The J-integral values indicate the maximum crack tip loads being reached during stationary cooling following each HHF pulse at $20 \mathrm{MW} / \mathrm{m}^{2}$. Both graphs clearly exhibit a significant impact of monoblock dimension, in particular, the monoblock width $w$ at both positions. At the free surface edge of the crack, the monoblock thickness $t$ affects the J-integral as well. It is found that armor failure by deep cracking would not be a critical concern anymore, provided that the monoblock size can be reduced down to $t=4 \mathrm{~mm}$ and $w=23 \mathrm{~mm}$. In this case, the crack is expected to cease to grow at the depth of $1.5 \mathrm{~mm}$ at the most where J-integral (crack tip extension energy) begins to go below the value of critical fracture energy. 

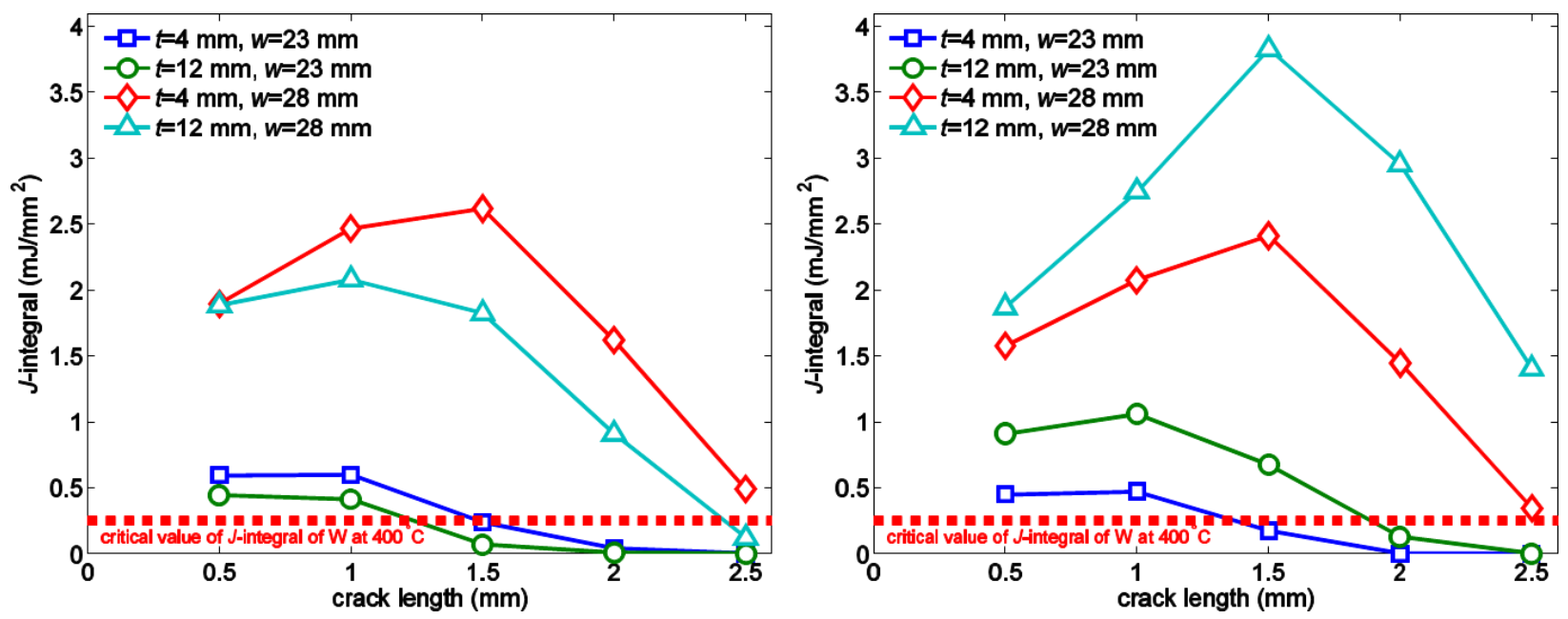

Figure 4. J-integral values at the tip of a crack initiated at the armor surface and extending in the vertical direction (left: at the symmetry plane, right: at the free surface edge).

On the contrary, the trend of J-integral assessed for the larger monoblock dimensions implicates that the ITER-type monoblock with the width of $w=28 \mathrm{~mm}$ will likely be subjected to high risk of armor cracking leading to deep self-castellation up to the interlayer. This feature has already been observed in several previous HHF tests [4, 5, 6, 7].

Moreover, it turned out that the monoblock size had a considerable structural effect on the plastic deformation behavior of the soft copper interlayer. Figure 5 shows the evolution of accumulated equivalent plastic strain in the copper interlayer during the first five HHF load cycles at 10 and $20 \mathrm{MW} / \mathrm{m}^{2}$, respectively, plotted for four different combinations of width and thickness. All strain values were calculated at the mid-point of the line formed by intersection of the $1^{\text {st }}$ and $2^{\text {nd }}$ planes of symmetry in the interlayer. It is clearly seen that the cyclic increment as well as the magnitude of plastic strain are modified by the monoblock dimensions.

The assessed values of plastic strain range and fatigue lifetime are summarized in Table 4. The PFC with the smallest dimension $(t=4 \mathrm{~mm}, w=23 \mathrm{~mm})$ exhibits the most beneficial effect while the largest dimension leads to the highest plastic fatigue risk. This trend is in line with that of the armor fatigue and cracking behaviors discussed above. Differently from the armor failure case, however, it seems that the monoblock thickness $(t)$ has more impact than the width $(w)$ on the plastic fatigue of the interlayer. The fatigue lifetime of the interlayer fulfills the ITER specification at both 10 and $20 \mathrm{MW} / \mathrm{m}^{2}$. It should be noted that the plastic strains were calculated at a position in the inner bulk. Near the free surface edge of the bond interface, the local plastic 
strain will be strongly increased resulting in strong reduction of local fatigue lifetime. This result is estimated with fatigue curve fitted with experimental data. If a design curve (lifetime divided by 20) is applied, the predicted lifetime will not fulfil the ITER specifications.
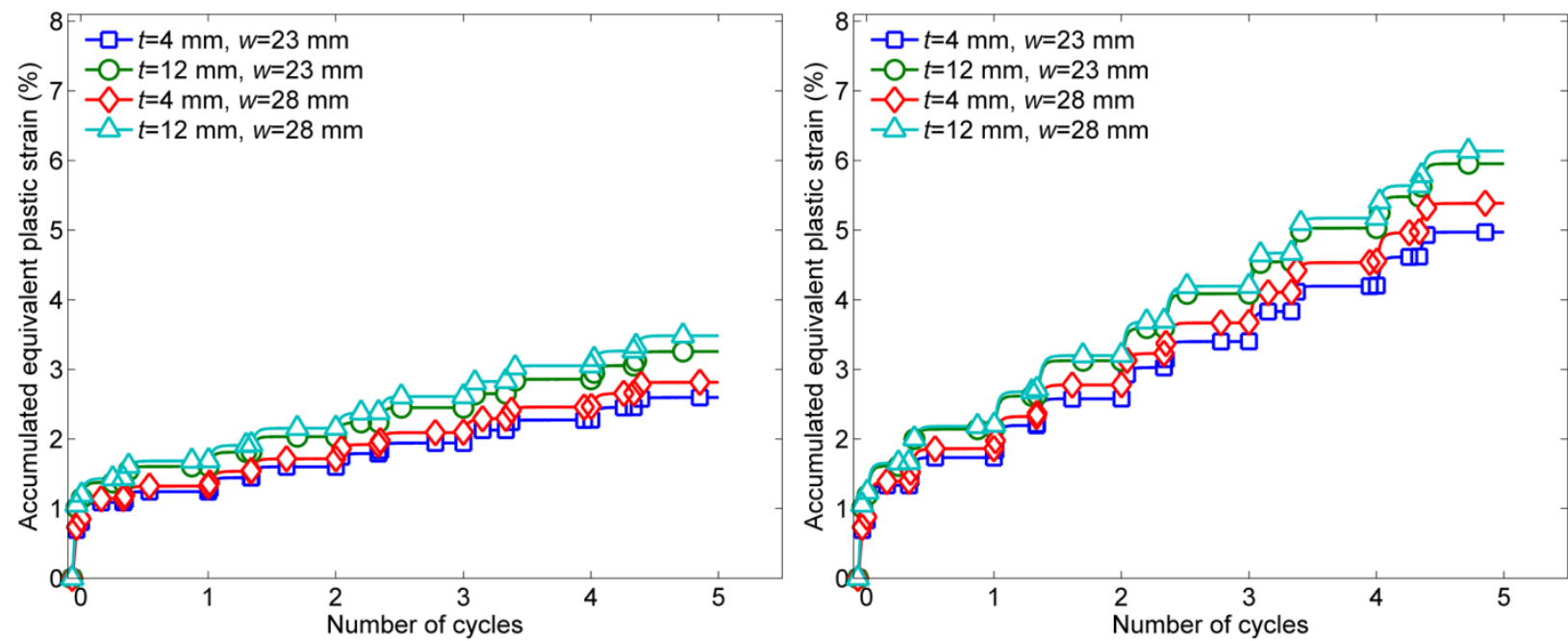

Figure 5. Accumulated equivalent plastic strain in the copper interlayer with respect to HHF (10 (left), $20 \mathrm{MW} / \mathrm{m}^{2}$ (right)) cycle numbers as a function of tungsten monoblock dimensions. The markers in the picture are only used for selected data point for a better illustration.

Table 4 Equivalent plastic strain range [\%] (corresponding plastic fatigue lifetime ${ }^{*}$ ) of the copper interlayer.

\begin{tabular}{|c|c|c|c|c|}
\hline Dimension $(\mathrm{mm})$ & $t=4, w=23$ & $t=12, w=23$ & $t=4, w=28$ & $t=12, w=28$ \\
\hline $10 \mathrm{MW} / \mathrm{m}^{2}$ & $\begin{array}{c}0.16 \\
\left(2.3 \times 10^{4} \text { cycles }\right)\end{array}$ & $\begin{array}{c}0.20 \\
\left(1.6 \times 10^{4}\right)\end{array}$ & $\begin{array}{c}0.18 \\
\left(1.9 \times 10^{4}\right)\end{array}$ & $\begin{array}{c}0.22 \\
\left(1.4 \times 10^{4}\right)\end{array}$ \\
\hline $20 \mathrm{MW} / \mathrm{m}^{2}$ & $\begin{array}{c}0.39 \\
\left(5.0 \times 10^{3}\right)\end{array}$ & $\begin{array}{c}0.46 \\
\left(3.6 \times 10^{3}\right)\end{array}$ & $\begin{array}{c}0.42 \\
\left(4.2 \times 10^{3}\right)\end{array}$ & $\begin{array}{c}0.48 \\
\left(3.4 \times 10^{3}\right)\end{array}$ \\
\hline
\end{tabular}

*Fatigue lifetime was estimated using the experimental low cycle fatigue data of copper in [20].

\subsection{Impact of the sacrificial armor thickness}

Sacrificial armor thickness $(a)$ is an important design parameter as it directly affects the surface layer temperature of the tungsten armor. The sacrificial armor thickness decreases continuously during fusion operation as a result of surface erosion. If the initial thickness of $a$ is defined too 
large, the surface region of the armor would be overheated leading to undesired recrystallization and thus loss of original properties. On the other hand, the armor should have a sufficiently large initial thickness in order to provide a sufficiently long erosion lifetime. Therefore, assessment of thermal and structural impact of the sacrificial armor thickness is an important design concern. Figure 6 shows the maximum temperature at the armor surface as a function of armor thickness ranging from 1 to $10 \mathrm{~mm}$ under two different HHF loads, 10 and $20 \mathrm{MW} / \mathrm{m}^{2}$. For $20 \mathrm{MW} / \mathrm{m}^{2}$, the temperature values at the center of the armor surface are also plotted for comparison. Radiative cooling effect was also taken into account. The monoblock width $(w)$, thickness $(t)$ and tube inner diameter $(d)$ were fixed at $23 \mathrm{~mm}, 4 \mathrm{~mm}$ and $12 \mathrm{~mm}$, respectively. As expected, the surface temperature increases nearly proportionally with the armor thickness. At $10 \mathrm{MW} / \mathrm{m}^{2}$, the maximum surface temperature is still below the recrystallization temperature $\left(1300{ }^{\circ} \mathrm{C}\right)$ of typical tungsten materials for the whole armor thickness range considered. At $20 \mathrm{MW} / \mathrm{m}^{2}$, the overall surface temperature begins to exceed the recrystallization temperature when the thickness is increased larger than $4 \mathrm{~mm}$. At the thickness of $7 \mathrm{~mm}$, the surface temperature is reaching nearly $2000{ }^{\circ} \mathrm{C}$ which seems unacceptably high. From the vertical temperature profile the depth of recrystallized layer can be roughly estimated. Assuming a sufficiently long heating duration accumulated at $20 \mathrm{MW} / \mathrm{m}^{2}$, the recrystallized depth increases from 0 to $6 \mathrm{~mm}$ for the whole thickness range. The in-plane temperature gradient on the surface decreases monotonically as the armor thickness increases. 


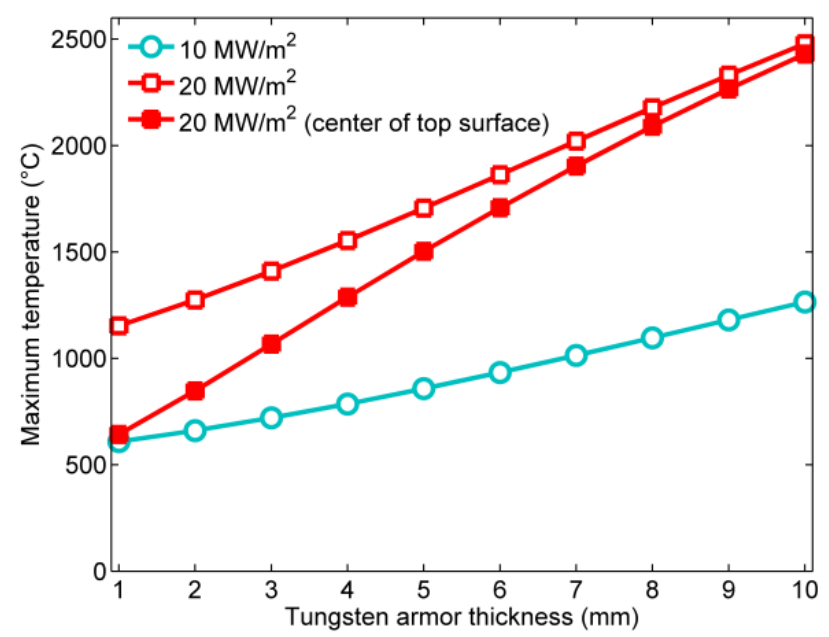

Figure 6 Maximum temperature at the armor surface plotted for a range of sacrificial armor thickness $a$ (monoblock width w: $23 \mathrm{~mm}$, monoblock thickness t: $4 \mathrm{~mm}$, tube inner diameter d: $12 \mathrm{~mm})$.

Figure 7 shows the maximum temperature in the copper interlayer and the $\mathrm{CuCrZr}$ tube, respectively, as a function of armor thickness ranging from 1 to $10 \mathrm{~mm}$ under two different HHF loads $\left(10\right.$ and $\left.20 \mathrm{MW} / \mathrm{m}^{2}\right)$. As in Figure 6 , the width $w$, thickness $t$ and tube diameter $d$ were fixed at $23 \mathrm{~mm}, 4 \mathrm{~mm}$ and $12 \mathrm{~mm}$, respectively. It is seen that the variation of armor thickness has no major impact on the heat sink temperature. 


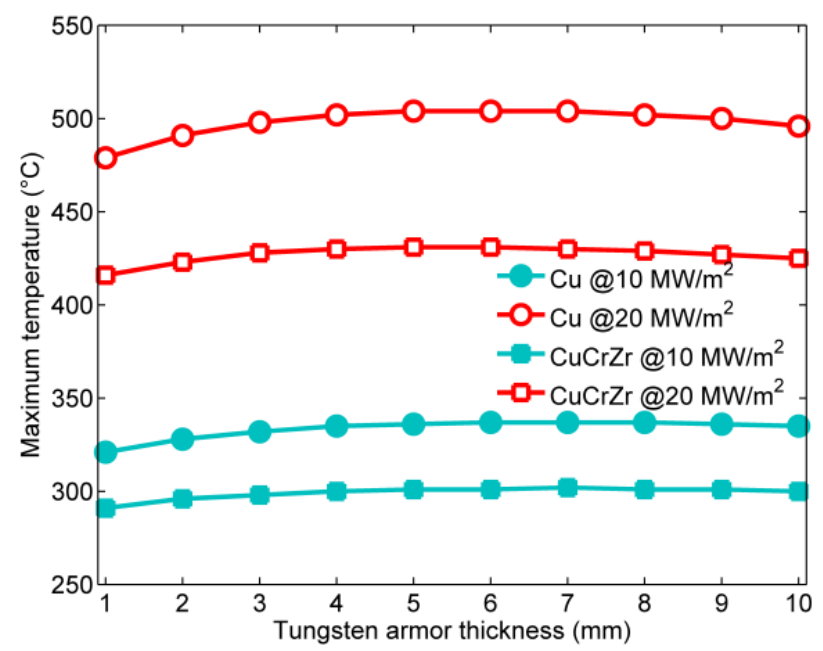

Figure 7. Maximum temperature in the copper interlayer and the cooling tube plotted for a range of sacrificial armor thickness $a$ (monoblock width $w: 23 \mathrm{~mm}$, monoblock thickness $t: 4 \mathrm{~mm}$, tube inner diameter $d: 12 \mathrm{~mm})$.

Figure 8 shows the incremental evolution of plastic deformation at the armor top surface during the first five $\mathrm{HHF}$ loading cycles at $20 \mathrm{MW} / \mathrm{m}^{2}$. Plotted are accumulated equivalent plastic strain values computed at two selected surface positions, namely, at the center (left) and the edge (right) of the axial mid-line as indicated in Figure 1. Plastic strain values obtained for five different thicknesses of the sacrificial armor are compared. The graphs show that plastic strain at the armor surface increases monotonically as the thickness of the sacrificial armor increases. For armor thickness smaller than $4 \mathrm{~mm}$, only negligibly small plastic strain is produced by the initial load, but the armor surface readily enters into a purely elastic state due to the shakedown effect and remains further elastic in the rest period of the HHF loading cycles. 

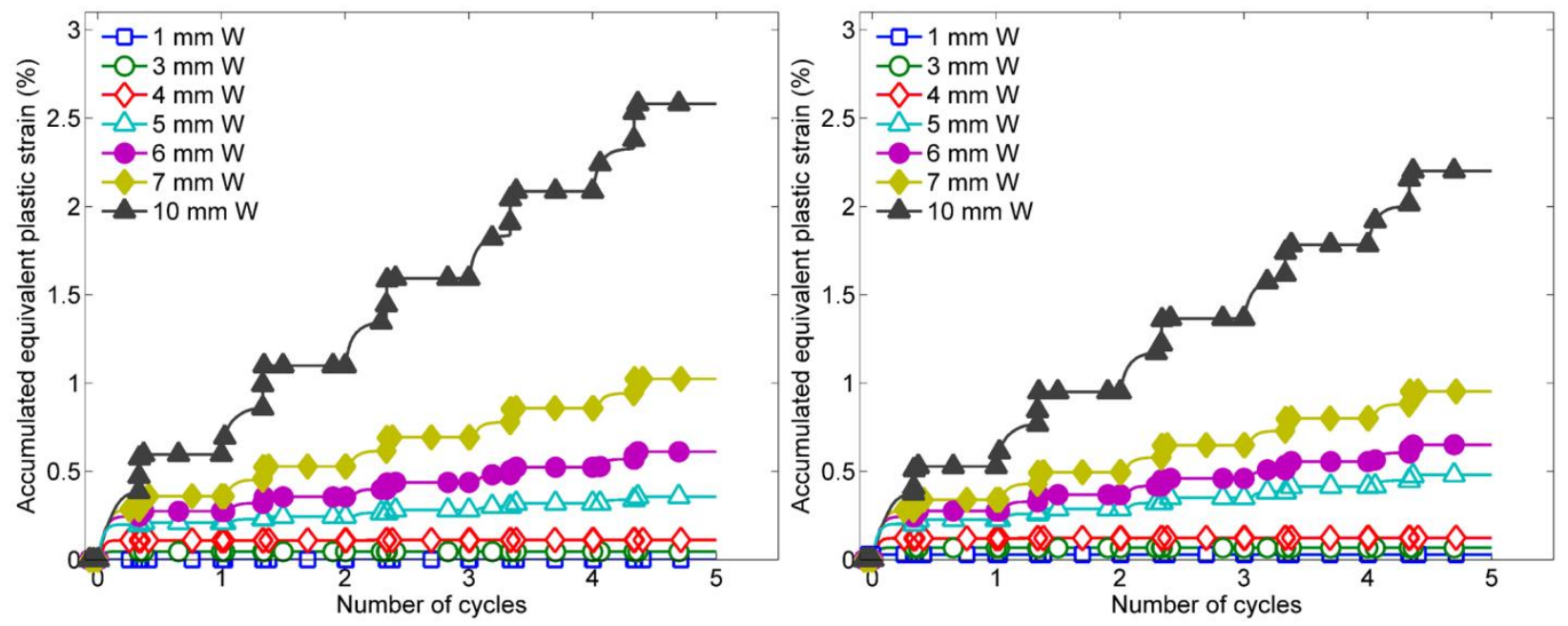

Figure 8. Evolution of accumulated equivalent plastic strain at two armor surface positions (left: center, right: edge) during the first five HHF loading cycles at $20 \mathrm{MW} / \mathrm{m}^{2}$. The markers in the picture are only used for selected data point for a better illustration.

In Table 5 the saturated plastic strain range (equivalent strain) and the predicted fatigue lifetime at the center and the edge position on the armor surface under cyclic HHF loads of $20 \mathrm{MW} / \mathrm{m}^{2}$ are summarized for seven different armor thicknesses. These are conservative estimations based on room temperature fatigue life data. As expected from Figure 8, armors with a thickness smaller than $4 \mathrm{~mm}$ are predicted not to experience any plastic fatigue failure at all. According to these results, it seems that for PFCs with an armor thickness up to $6 \mathrm{~mm}$ there would be no critical risk of failure with regard to cracking and fracture of the armor. However, it should be noted that plastic straining at the surface of a divertor with a larger armor thickness occurs at a higher temperature, at which tungsten is more ductile and thus the estimation listed in Table 5 is more conservative with increasing the armor thickness. Therefore no single correlation between the armor thickness (> $4 \mathrm{~mm}$ ) and its lifetime can be made before the material data for evaluating the thermo-mechanical fatigue of $\mathrm{W}$ is available.

Table 5. Equivalent plastic strain range (\%) and predicted LCF fatigue lifetime* at two armor surface positions (center and edge of the mid-line) under HHF load at $20 \mathrm{MW} / \mathrm{m}^{2}$. Results are 
comapred for five different armor thicknesses (monoblock width $w: 23 \mathrm{~mm}$, monoblock thickness $t$ : $4 \mathrm{~mm}$, tube inner diameter $d: 12 \mathrm{~mm}$ ).

\begin{tabular}{|c|c|c|c|c|}
\hline & \multicolumn{2}{|c|}{ center } & \multicolumn{2}{c|}{ edge } \\
\hline Armor thickness & $\Delta \varepsilon_{\mathrm{p}}(\%)$ & $\mathrm{N}_{\mathrm{f}}($ cycles $)$ & $\Delta \varepsilon_{\mathrm{p}}(\%)$ & $\mathrm{N}_{\mathrm{f}}$ (cycles) \\
\hline $1,3,4(\mathrm{~mm})$ & 0 & No failure & 0 & No failure \\
\hline 5 & 0.019 & 5227 & 0.032 & 889 \\
\hline 6 & 0.043 & 329 & 0.048 & 242 \\
\hline 7 & 0.082 & 39 & 0.076 & 52 \\
\hline 10 & 0.25 & 1 & 0.21 & 1 \\
\hline
\end{tabular}

*LCF lifetime is predicted using the LCF data of tungsten at room temperature [20].

Figure 9 shows the incremental evolution of accumulated equivalent plastic strain in the copper interlayer during the first five HHF loading cycles at 10 (left) and 20 (right) MW/m². The rate of plastic strain accumulation slightly increases with the thickness up to $3 \mathrm{~mm}$, and then decreases slightly beyond $3 \mathrm{~mm}$. If the armor thickness is reduced to $3 \mathrm{~mm}$ due to erosion, the risk of plastic fatigue in the copper interlayer will be increased. However, the difference is small (especially at $10 \mathrm{MW} / \mathrm{m}^{2}$ ) indicating that the structural impact of the armor thickness on the fatigue of the copper interlayer is not significant.
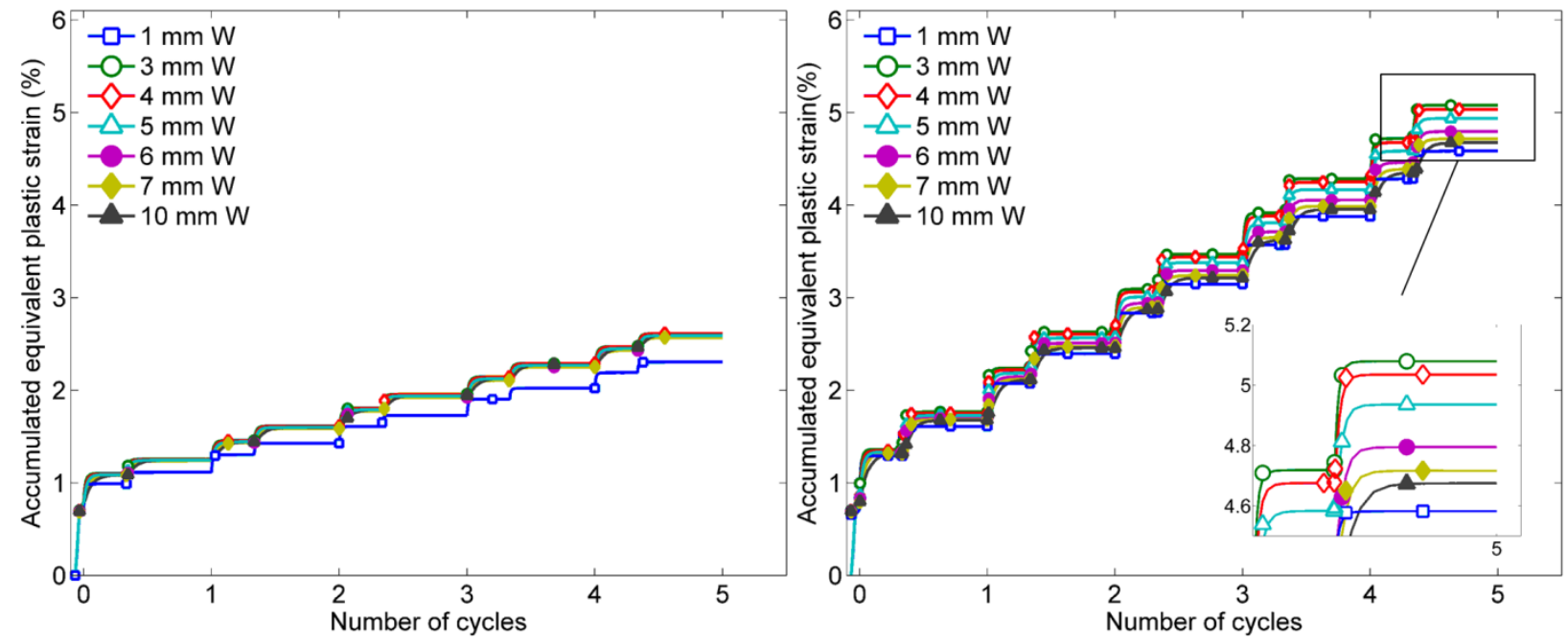

Figure 9. Accumulated equivalent plastic strain in the copper interlayer during the first five HHF loading cycles at 10 (left) and 20 (right) $\mathrm{MW} / \mathrm{m}^{2}$ plotted for different armor thicknesses 
(monoblock width $w: 23 \mathrm{~mm}$, monoblock thickness $t: 4 \mathrm{~mm}$, tube inner diameter $d: 12 \mathrm{~mm}$ ). The markers in the picture are only used for selected data point for a better illustration.

\subsection{Impact of the cooling tube diameter}

Two options of cooling tube inner diameter were investigated (10 and $12 \mathrm{~mm})$. It is noted that these two diameters have been the most widely adopted size of PFC cooling tube including ITER. Three different combinations of dimensions were evaluated as listed in Table 6 (case 1, 2 and 3). In the case 3, the height $h$ and the width $w$ are reduced in order to keep the same sacrificial armor thickness and armor shoulder thickness as in case 1 so that purely the effect of tube diameter can be identified. In case 2 , only the tube diameter is reduced compared with case 1 , thus the armor thickness becomes larger than in case 1 and case 3 accordingly.

In Table 6 the maximum temperatures in the individual parts of the PFC under $20 \mathrm{MW} / \mathrm{m}^{2}$ are compared between the three dimension cases.

Table 6. Maximum temperature $\left({ }^{\circ} \mathrm{C}\right)$ at different parts of the divertor for different inner diameters and dimensions of tungsten monoblock at $20 \mathrm{MW} / \mathrm{m}^{2}$.

\begin{tabular}{|c|c|c|c|}
\hline & $\begin{array}{c}\text { Case 1) } \varnothing=12 \mathrm{~mm} \\
h=25 \mathrm{~mm}, w=23 \mathrm{~mm}\end{array}$ & $\begin{array}{c}\text { Case 2) } \varnothing=10 \mathrm{~mm} \\
h=25 \mathrm{~mm}, w=23 \mathrm{~mm}\end{array}$ & $\begin{array}{c}\text { Case 3) } \emptyset=10 \mathrm{~mm} \\
h=23 \mathrm{~mm}, w=21 \mathrm{~mm}\end{array}$ \\
\hline Tungsten armor & 1723 & 1930 & 1683 \\
\hline Copper interlayer & 506 & 520 & 509 \\
\hline CuCrZr tube & 432 & 447 & 434 \\
\hline
\end{tabular}

Figure 10 shows the incremental evolution of accumulated equivalent plastic strain at two positions (left: center, right: edge) on the armor surface for the first five HHF loading cycles at $20 \mathrm{MW} / \mathrm{m}^{2}$. Plastic strains are compared for the three cases of dimension combinations as described in Table 6. The case 2 exhibits the largest magnitude and increment of plastic strain whereas the case 3 results in the smallest plastic strain and strain amplitude. This trend implies that the driving force of plastic fatigue at the armor surface is proportional to surface temperature regardless of how the dimensional parameters are actually combined. For a given armor 
thickness, smaller diameter looks advantageous than larger one with respect to fatigue load on the armor surface.
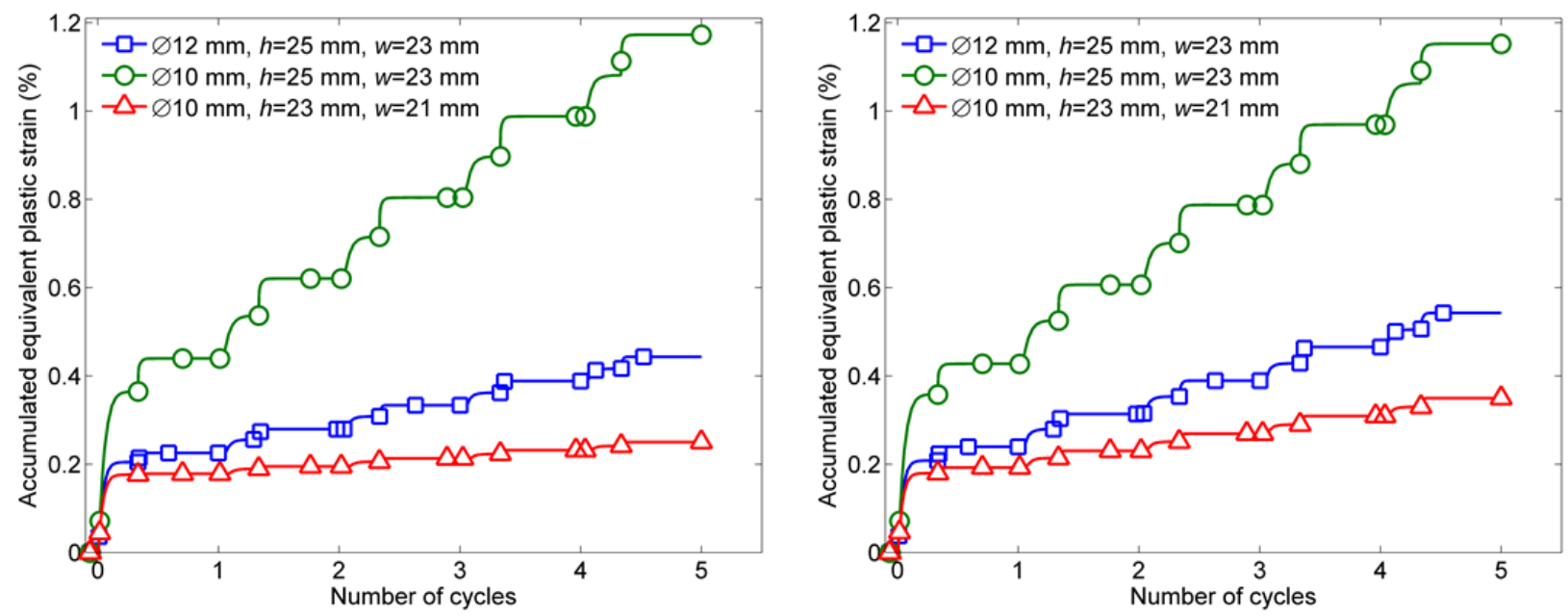

Figure 10. Evolution of accumulated equivalent plastic strain at two positions (left: center, right: edge) on the armor surface for the first five HHF loading cycles at $20 \mathrm{MW} / \mathrm{m}^{2}$. The markers in the picture are only used for selected data point for a better illustration.

Figure 11 shows the incremental evolution of accumulated equivalent plastic strain in the copper interlayer at $20 \mathrm{MW} / \mathrm{m}^{2}$. Plastic strains are compared for the three dimension cases. Obviously, it seems that the difference in dimensions (e.g. tube diameter) considered here is not big enough to cause any remarkable impact on the plastic deformation of the copper interlayer. 


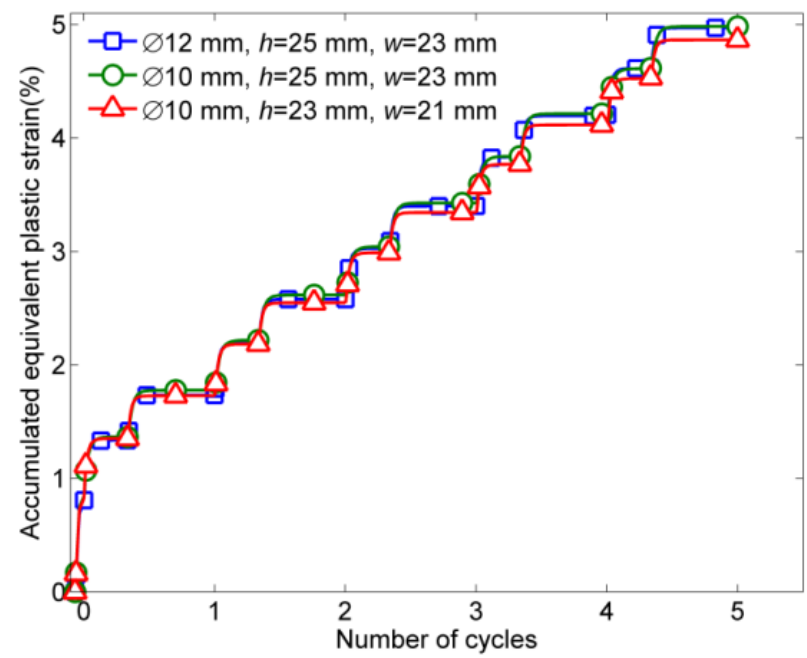

Figure 11. Evolution of accumulated equivalent plastic strain in the copper interlayer for the first five $\mathrm{HHF}$ loading cycles at $20 \mathrm{MW} / \mathrm{m}^{2}$. The markers in the picture are only used for selected data point for a better illustration.

\section{Conclusions}

In this paper, an extensive computational study was presented about the structural impact of the dimensional parameters on the failure behavior of an ITER-type divertor target PFC under HHF loads of 10 and $20 \mathrm{MW} / \mathrm{m}^{2}$. As variable dimensional parameters the width and the thickness of the tungsten monoblock, the thickness of sacrificial armor and the inner diameter of the cooling tube were considered. The key findings are summarized in the following:

1. Decreasing the width and thickness of monoblock leads to a lower risk of deep cracking in the armor and plastic fatigue in copper interlayer. To reduce the risk of deep cracking, it is much more efficient to decrease the width of monoblock than the thickness of monoblock.

2. Decreasing the thickness of tungsten armor leads to a lower temperature at the top surface, thus a smaller plastic strain accumulation at the top surface (at $20 \mathrm{MW} / \mathrm{m}^{2}$ ), but it has no significant impact on the thermo-mechanical behavior of the copper interlayer. 
3. Decreasing the inner diameter of the tube remaining the same armor thickness and the shoulder thickness leads a decrease of plastic strain accumulation at top surface of monoblock.

According to the parametric predictions of this work, monoblock with a smaller size turned out to experience lower failure rates in terms of both brittle cracking of tungsten and plastic fatigue of copper interlayer compared to larger ones. This trend is generally in line with the previous experimental observations. Dedicated HHF test campaigns are foreseen in near future to verify the present computational predictions in the framework of European DEMO divertor project.

\section{Acknowledgement}

This work has been carried out within the framework of the EUROfusion Consortium and has received funding from the Euratom research and training program 2014-2018 under grant agreement No 633053. The views and opinions expressed herein do not necessarily reflect those of the European Commission.

\section{Bibliography}

[1] T. Hirai, F. Escourbiac, S. Carpentier-Chouchana, A. Fedosov, L. Ferrand, T. Jokinen, V. Komarov, A. Kukushkin, M. Merola, R. Mitteau, R. Pitts, W. Shu, M. Sugihara, B. Riccardi, S. Suzuki, R. Villari, "ITER tungsten divertor design development and qualification program," Fusion Eng. Des., vol. 88, p. $1798-1801,2013$.

[2] J.H. You et al., "Conceptual design studies for the European DEMO divertor: Rationale and first results," Fus.Eng.Des., p. doi:10.1016/j.fusengdes.2015.11.012, 2015.

[3] J. H. You, E. Visca, C. Bachmann, T. Barrett, F. Crescenzi, M. Fursdon, H. Greuner, D. Guilhem, P. Languille, M. Li, S. McIntosh, A. v. Müller, J. Reiser, M. Richou and M. Rieth, "European DEMO divertor target: Operational requirements and material-design interface," Nucl. Mater. Energy, p. http://dx.doi.org/10.1016/j.nme.2016.02.005, 2016.

[4] P. Gavila, B.Riccardi, G. Pintsuk, G.Ritz, V. Kuznetsov, A. Durocher, "High heat flux testing of EU tungsten monoblock mock-ups for the ITER divertor," Fus. Eng. Des., Vols. 98-99, pp. 1305-1309, 2015. 
[5] G. Pintsuk, M. Bednarek, P. Gavila, S. Gerzoskovitz, J. Linke, P. Lorenzetto, B. Riccardi and F. Escourbia, "Characterization of ITER tungsten qualification mock-ups exposed tohigh cyclic thermal loads," Fus. Eng. Des., Vols. 98-99, pp. 1384-1388, 2015.

[6] B. Riccardi, R. Giniatulin, N. Klimov, V. Koidan and A. Loarte, "Preliminary results of the experimental study of PFCs exposure to ELMs-like transient loads followed by high heat flux thermal fatigue," Fus. Eng. Des., vol. 86, pp. 1665-1668, 2011.

[7] G. Pintsuk, I. Bobin-Vastrab, S. Constans, P. Gavila, M. Rödig and B. Riccardi, "Qualification and postmortem characterization of tungsten mock-ups exposed to cyclic high heat flux loading," Fus.Eng.Des., vol. 88, pp. 1858-1861, 2013.

[8] E. Visca, E. Cacciotti, A. Komarov, S. Libera, N. Litunovsky, A. Makhankov, A. Mancini, M. Merola, A. Pizzuto, B. Riccardi and S. Roccella, "Manufacturing, testing and post-test examination of ITER divertor vertical target W small scale mock-ups," Fus. Eng. Des., vol. 86, p. 1591-1594, 2011.

[9] K. Ezato, S. Suzuki, Y. Seki, K. Mohri, K. Yokoyama, F. Escourbiac,T. Hirai, V. Kuznetcovc, "Progress of ITER full tungsten divertor technology qualification in Japan," Fus. Eng. Des., Vols. 98-99, pp. 12811284, 2015.

[10] P. Gavila, B. Riccardi, S. Constans, J. Jouvelot, I. B. Vastra, M. Missirlian and M. Richou, "High heat flux testing of mock-ups for a full tungsten ITER divertor," Fus.Eng.Des., vol. 86, pp. 1652-1655, 2011.

[11] T. Hirai, F. Escourbiac, V. Barabash, A. Durocher, A. Fedosov, L. Ferrand, T. Jokinen,V. Komarov, M. Merola, S. Carpentier-Chouchana, N. Arkhipov, V. Kuznetcov, A. Volodin, S. Suzuki, K. Ezato, Y. Seki, B. Riccardi, M. Bednarek, P. Gavila, "Status of technology R\&D for the ITER tungsten divertor monoblock," J. Nucl. Mater., vol. 463, pp. 1248-1251, 2015.

[12] M. Li and J.-H. You, "Interpretation of the deep cracking phenomenon of tungsten monoblock targets observed in high-heat-flux fatigue tests at 20 MW/m²," Fus.Eng.Des., vol. 101, pp. 1-8, 2015.

[13] M. Li, E. Werner and J.-H. You, "Fracture mechanical analysis of tungsten armor failure of awatercooled divertor target," Fus.Eng.Des, vol. 89, pp. 2716-2725, 2014.

[14] M. Li, E. Werner and J.-H. You, "Low cycle fatigue behavior of ITER-like divertor target under DEMOrelevant operation conditions," Fus. Eng. Des., vol. 90, pp. 88-96, 2015.

[15] M. Roedig, W. Kuehnlein, J. Linke, D. Pitzer, M. Merola, E. Rigal, B. Schedler and E. Visca, "Post irradiation testing of samples from the irradiation experiments PARIDE 3 and PARIDE 4," J. Nucl. Mater., Vols. 329-333, pp. 766-770, 2004. 
[16] F. Crescenzi, C. Bachmann, M. Richou, S. Roccella, E. Visca and J.-H. You, "Design study of ITER-like divertor target for DEMO," Fus.Eng.Des, Vols. 98-99, pp. 1263-1266, 2015.

[17] Systèmes, Dassault, ABAQUS 6.14 Documentation, Providence, RI, USA, 2014.

[18] ITER structural design criteria for in-vessel components (SDC-IC), "Appendix A: Materials design limit data," ITER, 2012.

[19] J.-H. You and M. Miskiewicz, "Material parameters of copper and CuCrZr alloy for cyclic plasticity at elevated temperatures," J. Nucl. Mater., vol. 373, pp. 269-274, 2008.

[20] ITER Document No.G74 M 16, "ITER Material Properties Handbook," 2005.

[21] E. N. Sieder and G. E. Tate, " Heat transfer and pressure drop of liquids in tubes," Indust. Eng. Chem. , vol. 28, p. 1429-1435, 1936.

[22] J. Thom, W. Walker, T. Fallon and G. Reising, "Boiling in sub-cooled water during flow up heated tubes or annuli," Proc. Inst. Mech. Engineers (London), vol. 180: Pt 3C, pp. 226-46, 1956-66. 